\title{
Doctors from ethnic minority backgrounds earn less than white colleagues
}

\author{
Tom Moberly UK editor
}

The BMJ

Doctors from ethnic minority backgrounds working in some roles are paid thousands of pounds less a year than their white colleagues, data from NHS Digital show. ${ }^{1}$

Asian or British Asian consultants earn 3.3\% less than their white counterparts, while black, African, Caribbean, and British black consultants earn $2.3 \%$ less and consultants from mixed or multiple ethnic groups earn $3.1 \%$ less.

Among less senior doctors, the differences are less marked. Among staff and specialty and associate specialist (SAS) doctors, black, African, Caribbean, and British black doctors, and doctors from mixed or multiple ethnic groups, earn less than their white counterparts, though those from other ethnic groups earn more.

Among doctors in training, doctors from mixed or multiple ethnic groups earn less than their white counterparts, but Asian or British Asian doctors, black, African, Caribbean, and British black doctors, and those from other ethnic groups earn more.

Differences also exist across other staff groups. Looking at the average difference across all staff, black, African, Caribbean, and British black NHS workers earn $6.8 \%$ less than their white counterparts. Black, African, Caribbean, and British black support staff earn $12.2 \%$ less, and black, African, Caribbean, and British black managers earn 14.2\% less. Asian or British Asian nurses earn $8.3 \%$ less than their white counterparts. Writing for The BMJ in September, John Appleby, director of research and chief economist at the Nuffield Trust, said that discrepancies between the pay of doctors of different ethnicities warranted further investigation and explanation. His own investigation found that the median basic pay for white consultants was $4.9 \%$ higher than for black and minority ethnic consultants. $^{2}$

1 Rimmer A. Black and Asian doctors earn less than their white colleagues, official NHS figures show. BMJ 2018;362:k4124. 10.1136/bmj.k4124 30266799

2 Appleby J. Ethnic pay gap among NHS doctors. BMJ 2018;362:k3586. 10.1136/bmj.k3586 30185418

Published by the BMJ Publishing Group Limited. For permission to use (where not already granted under a licence) please go to http://group.bmj.com/group/rights-licensing/ permissions 


\section{Figures}




\section{Average pay difference}

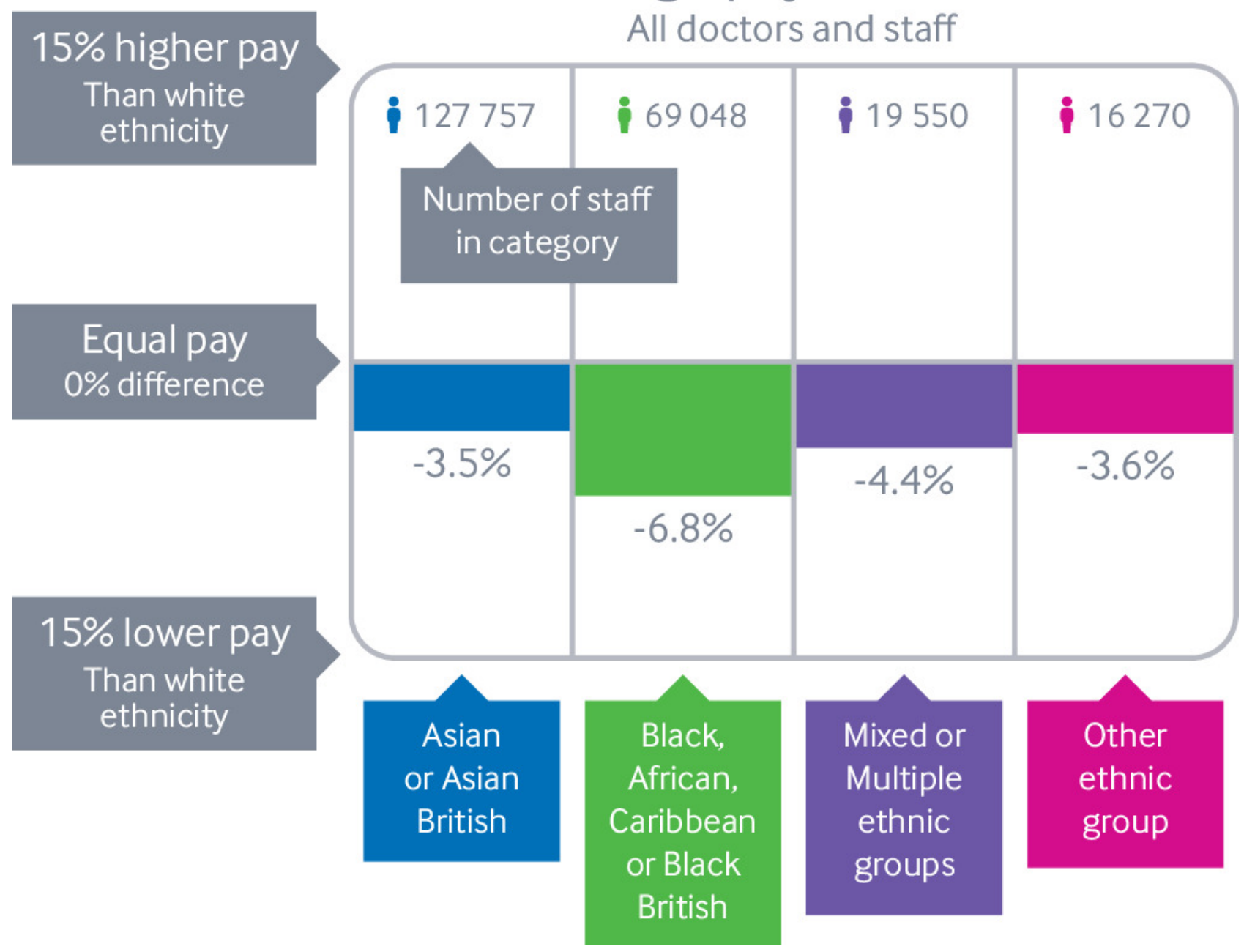

Doctors in training

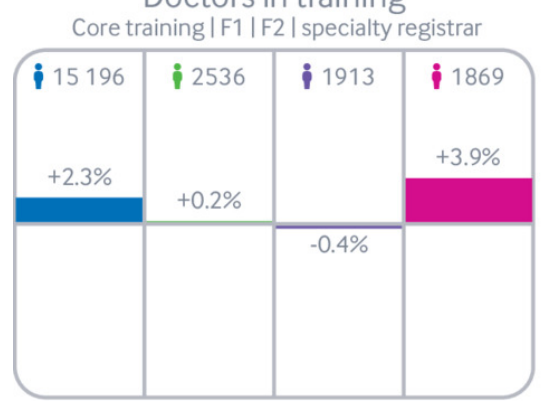

SAS doctors Specialty doctor $\mid$ associate specialist | staff grade

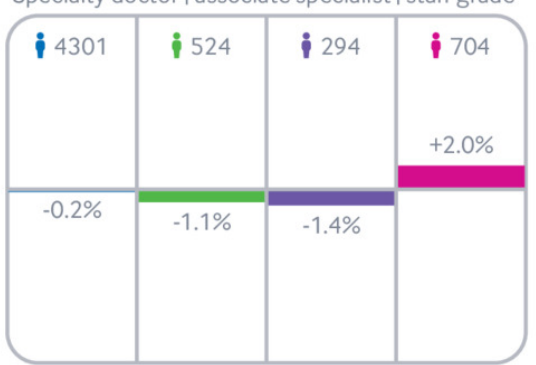

Consultants

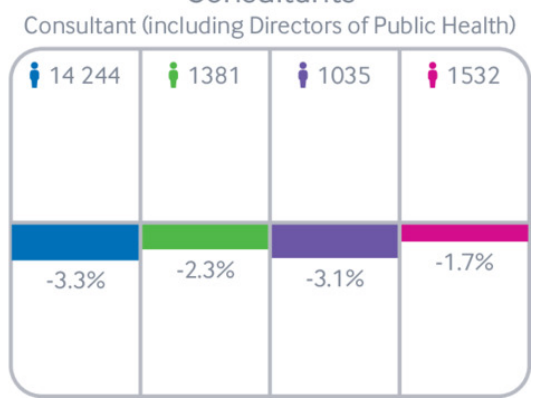




\section{Support staff}

Scientific, therapeutic and technical staff | Support to ambulance staff | Support to doctors, nurses and midwives I Support to ST\&T staff

Nurses, midwives, and health visitors

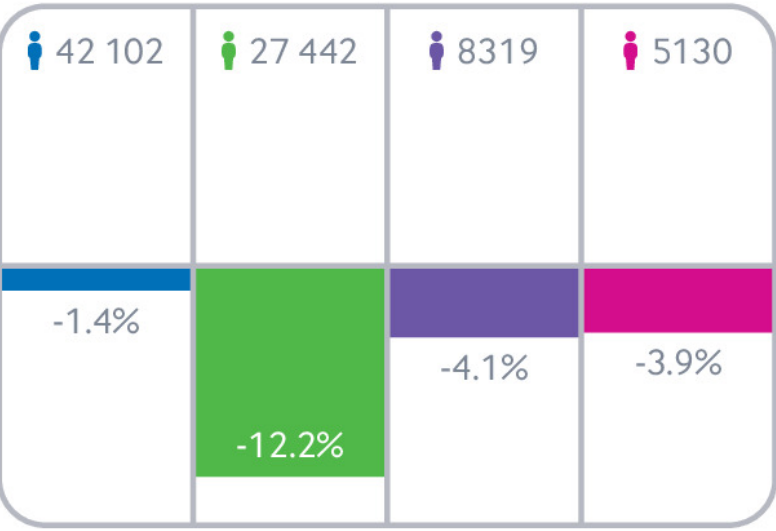

Managers

Managers | senior managers

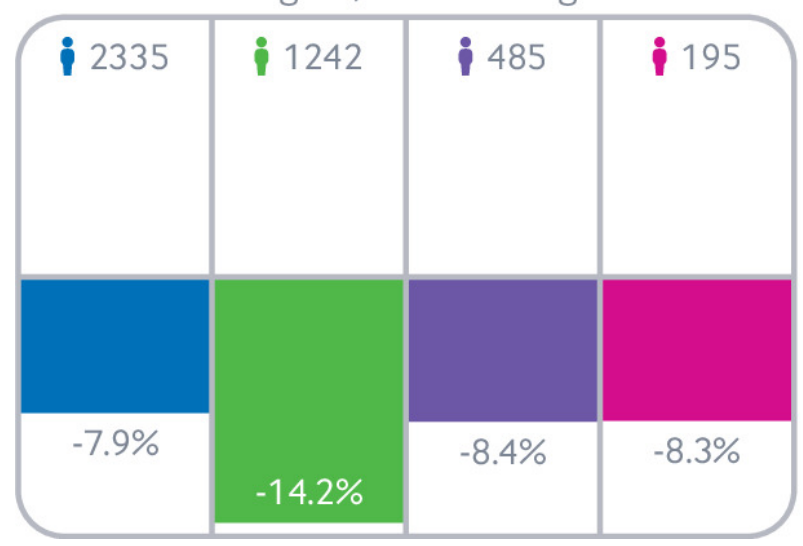

Other staff

Central functions | hotel, property and estates | other

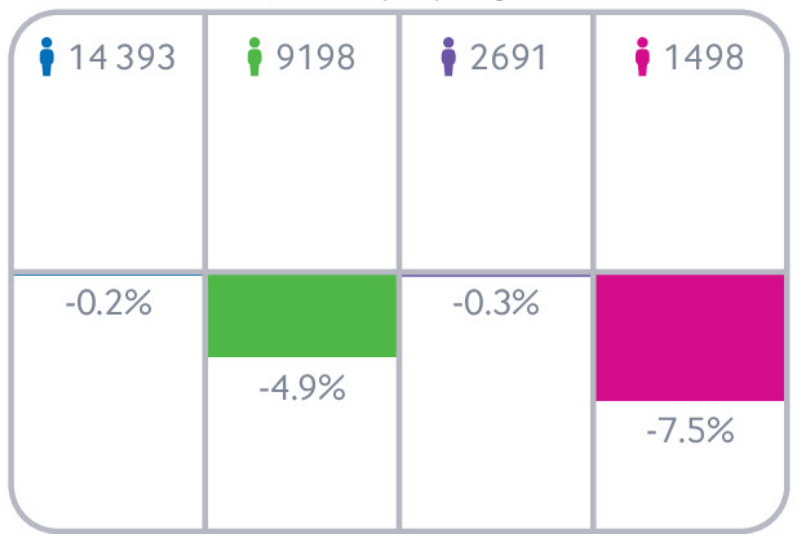

Im 